\title{
Development of methods for optimizing the parameters of the body of a fixed jaw crusher
}

\author{
Kostiantyn Zabolotnyi ${ }^{1, *}$, and Olena Panchenko ${ }^{1}$ \\ ${ }^{1}$ National Technical University Dnipro Polytechnic, 49005, Dnipro, Yavornytskoho Ave., 19, Ukraine
}

\begin{abstract}
By the example of justification of the design parameters of the fixed jaw body of the jaw crusher, the methods have been developed for choosing the optimal parameters according to the strength condition under restrictions on its mass. The practical value of the work is in development of the recommendations for designing the fixed jaw body, based on the criterion of minimum mass for the set tensile strength. It is shown that the use of the proposed recommendations allows to reduce the metal consumption of the jaw by $170-200 \%$.
\end{abstract}

\section{Introduction}

Designing mining machines provides for the solution of the main task of choosing the design parameters capable of ensuring the operability working capacity of these devices with regard to various requirements. As it is shown in the work [1], mechanical structures must be sufficiently rigid and strong with restrictions on their mass. The scientists of the Department of Mining Machines and Engineering specialize in finite element analysis of thin-walled reinforced structures; their knowledge has already helped production workers to solve the number of practical problems. So in work [2], using the methods of finite element analysis (FEM), the influence of the stiffness of the shoe brake on the contact pressure distribution is considered.

The FEM method allows not only to analyze the stress-strain state of structures, but also to solve the problems of parametrical and structural optimization. Let us demonstrate this by the example of a parametrical optimization of the jaw crusher with a simple movement of the jaw [3, 4], the design of which is shown in Figure 1. Here it is indicated: 1 - fixed jaw; 2 - bed; 3 - movable jaw; 4 - flywheel and drive pulley; 5 - motor; 6 - V-belt drive; 7 - adjusting device; 8 - rear toggle in the assembled state (safe one); 9 - connecting rod in the assembled state; 10 - front toggle; 11 - locking rod; 12 - control panel.

In the design development, an important issue is the optimization of the mass of the following assemblies: the fixed jaw, the movable jaw, taking into account the geometric parameters that determine their shape and dimensions under the set strength conditions.

Taking into consideration the fact that the designs of the movable and fixed jaws are similar, let us take the design of the fixed jaw body as an object of the analysis.

"Corresponding author: mmf@ua.fm 
Let us develop an algorithm for the parametrical optimization of the design of the crusher fixed jaw. Let us find the values of the geometrical parameters of the jaw, at which the minimum value of the body mass is reached.

The purpose of the study is the development of recommendations for the designing the fixed jaw of the jaw crusher.

In order to achieve the goal, it is necessary to solve the following subtasks:

1. To develop a mathematical model of the body of the crusher fixed jaw.

2. To develop an algorithm for optimizing the body of the fixed jaw of jaw crusher.

3. To develop recommendations for designing the body of the fixed jaw of jaw crusher.

Figure 2 shows a conceptual model of the fixed jaw body in the form of a steel casting, on one side of which there is a lining made of high-strength manganese steel, and on the opposite side there is a rib reinforcement of the wafer shape.

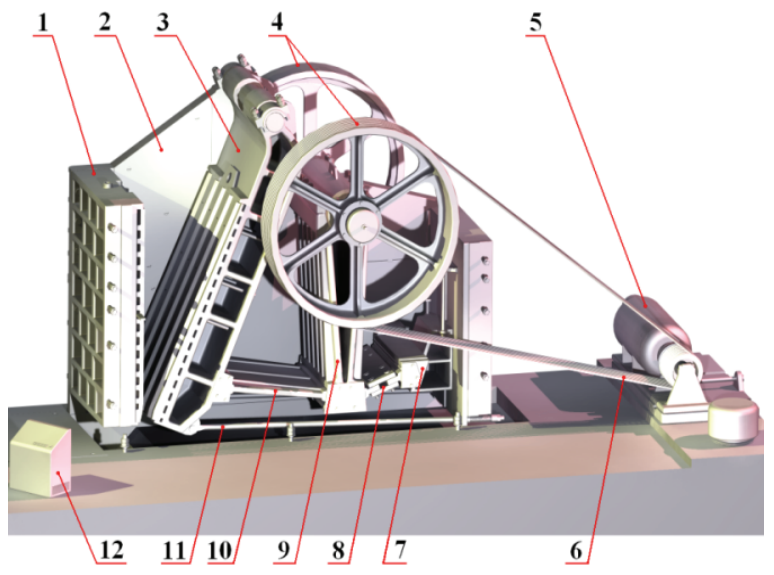

Fig. 1. Appearance of the jaw crusher with the simple movement of the jaw.

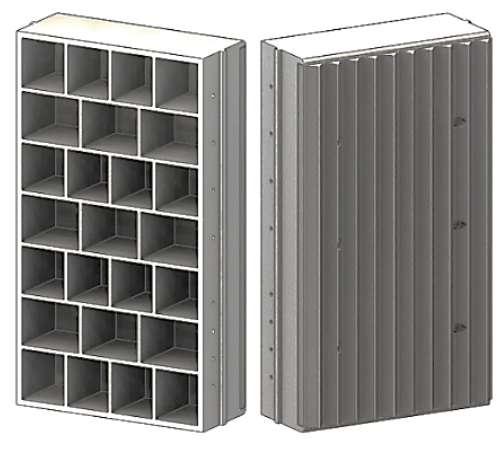

Fig. 2. Model of the body of the crusher fixed jaw.

The geometric shape of the body is determined taking into account the parameters controlled in the process of optimization (Fig. 3), their values are accepted on the basis on design considerations, in particular, these are the height $H$ and the length $L$ of the body, width $l_{\mathrm{c}}$ and height $\delta_{\mathrm{c}}$ of the ledges for connecting the jaw with the base. The parameter controlled during the optimization process can be the jaw thickness $\delta$. In addition, the functional limitations associated with such strength condition on equivalent stress as $\sigma_{\text {eq }} \leq[\sigma]$ must be taken into account.

The mathematical model of the construction under consideration can be represented by the following dependencies:

$$
\begin{gathered}
S=\delta / 12 ; \\
t=(0.6 \ldots 0.7) S ; \\
T_{1}=H-2 S / 7 ; \\
T_{2}=L-2 S / 4 ; \\
T_{3}=L-2 S / 3 .
\end{gathered}
$$




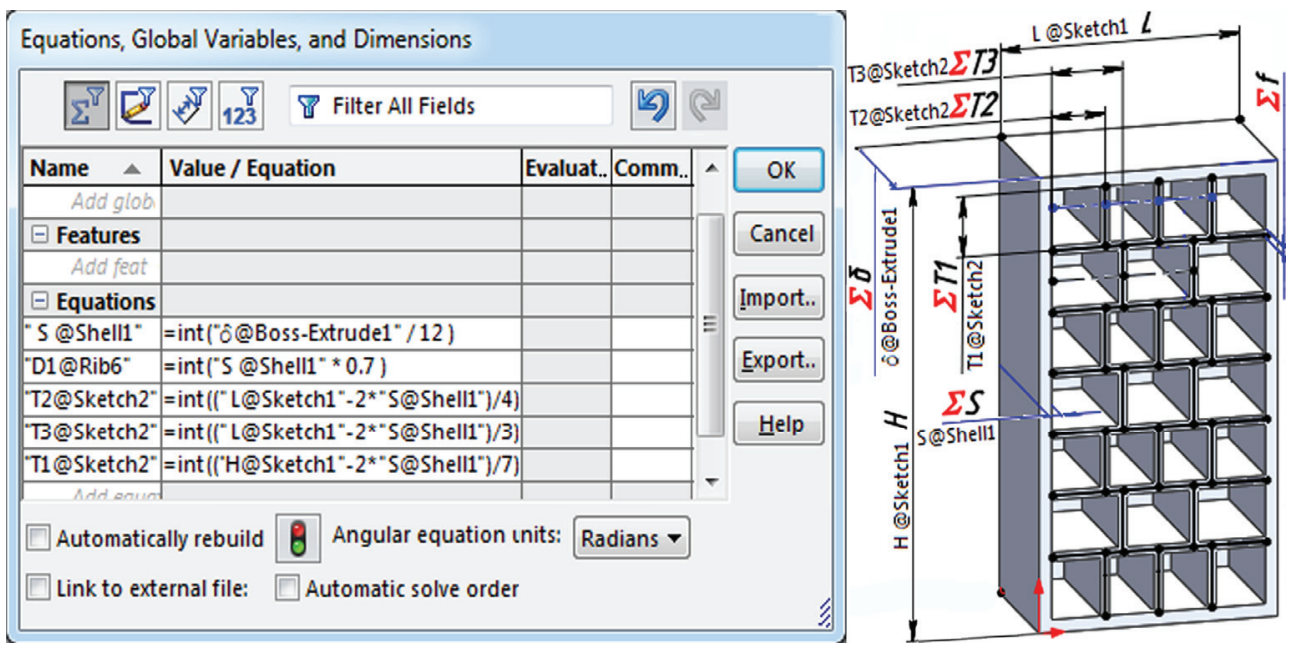

Fig. 3. Creating a parametric model of the hull of the fixed crusher jaw.

\section{Development of the algorithm for optimizing the body of the fixed jaw}

To determine the safety margin of the jaw body, we will perform a preliminary calculation of the stress-strain state. We use the finite element method implemented in the complex of software package SolidWorks Simulation (SolidWorks Education Class Pack s/n 9710009087238505XH6SPG92).

Figure 4 shows the finite element model of the body of a fixed jaw.

The following boundary conditions are used in the solution:

- Type of research "Static".

- The material of the jaw body - carbon steel cast.

- The created grid on a solid body, the grid, the global size of a finite element of which is equal to $20 \mathrm{~mm}$ (we assume that the rib thickness is the same and is divided in half: $40 / 2=20 \mathrm{~mm}$ ). The result obtained at the decision is estimated by analyzing the grid details. The criterion of its correctness is the condition under which the maximum aspect ratio of the finite element is less than or equal to 6 . As you can see, this parameter is 4 (Fig. 5), therefore, the size of the grid elements is chosen correctly.

- On the two given element surfaces of the connection element with the bed and the bottom face are "Fastenings"; from the "Additional" section, the "On flat faces" restriction type is selected with the condition of prohibiting displacements in the direction perpendicular to the faces.

- The operating load is selected as the pressure type "Perpendicular to the selected face", in the "Faces for pressure" window, we mark with the mouse the main jaw surface interacting with the lining, and in the "Pressure value" column, - the crushing pressure which is equal to $2.7 \mathrm{MPa}$.

- Calculation of voltage takes place in the menu "Simulation", "Perform".

- Plotting stress graphs.

- Setting the results for plotting the stress graphs using the sections of the program "Simulation", "Result tools", "Graph parameters ...", as well as by the setting in the section "Display Options" of the options "To display maximum note" and "Defined", the value of the lower limit voltage "Min" - 0, and of the upper limit "Max" - that is, the maximum allowable which is equal to $165 \mathrm{MPa}$. 


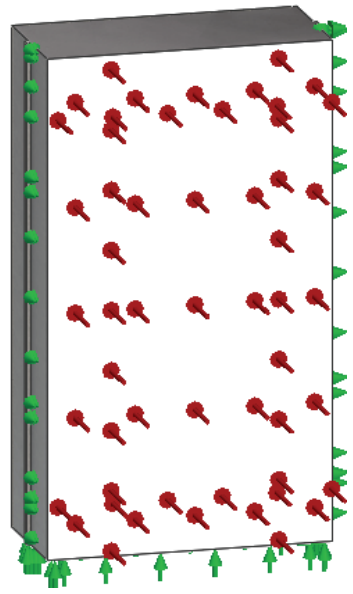

Fig. 4. Finite-element model of the body of the crusher fixed jaw.

\begin{tabular}{|l|l|}
\hline Mesh Details & \multicolumn{1}{|c|}{-r X } \\
\hline Study name & Static 1 \\
\hline Mesh type & Solid Mesh \\
\hline Mesher Used & Standard mesh \\
\hline Automatic Transition & Off \\
\hline Include Mesh Auto Loops & Off \\
\hline Jacobian points & 4 points \\
\hline Element size & $20 \mathrm{~mm}$ \\
\hline Tolerance & $5.33115 \mathrm{~mm}$ \\
\hline Mesh quality & High \\
\hline Total nodes & 979959 \\
\hline Total elements & 631476 \\
\hline Maximum Aspect Ratio & 4.4416 \\
\hline $\begin{array}{l}\text { Percentage of elements } \\
\text { with Aspect Ratio }<3\end{array}$ & 99.9 \\
\hline $\begin{array}{l}\text { Percentage of elements } \\
\text { with Aspect Ratio }>10\end{array}$ & 0 \\
\hline $\begin{array}{l}\text { \% of distorted elements } \\
\text { (Jacobian) }\end{array}$ & 0 \\
\hline
\end{tabular}

Fig. 5. Parameters of the finite element mesh.

The analysis of the stress-strain state in the body of the jaw shows that the equivalent stresses in the place of costal reinforcement do not exceed $30 \mathrm{MPa}$, when the yield strength is $250 \mathrm{MPa}$, which corresponds to safety margin 8 (Fig. 6). However, in some parts of the structure, which are stress concentrators, the equivalent stresses exceed those allowable, which is not critical for the entire structure as a whole, since the increase in stresses is associated with the peculiarities of the modeling by the finite element method.

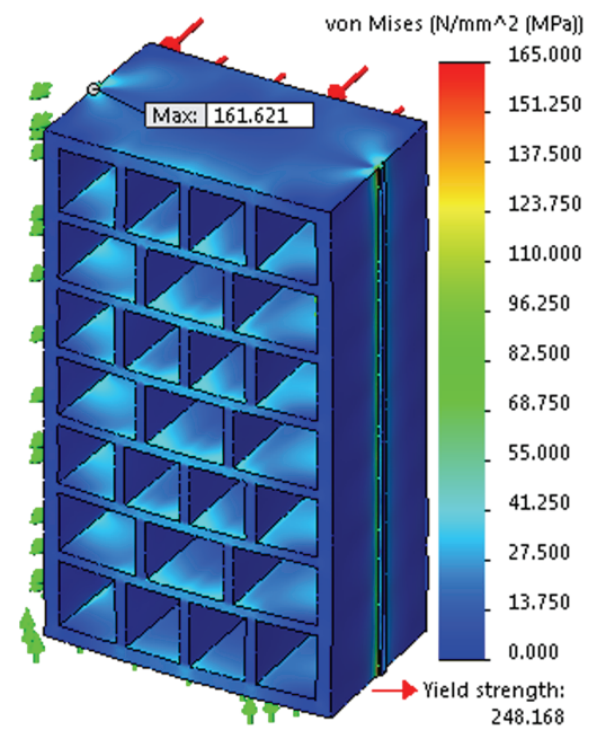

Fig. 6. The result of the calculation of the stress-strain state of the body of the crusher jaw.

The preliminary analysis of the results of solving the problem showed that the safety margin of the structure is too high and the body can be significantly lightened. 
Let us set the task: for the crusher size $900 \times 1200 \mathrm{~mm}$ with the given values of $H, L, l_{c}$, $\delta_{c}$ and $\sigma_{e q} \leq[\sigma]=165 \mathrm{MPa}$, we will find the value of the parameter $\delta$ ( $350 \mathrm{~mm} \leq \delta \leq 750 \mathrm{~mm}$ ) at which the body mass will be minimal.

The SolidWorks Simulation application software package provides an option to optimize the design, taking into account the criterion of the minimum of its mass while maintaining the specified margin of safety. Let the permissible stresses be $165 \mathrm{MPa}$, and the safety margin is 1.5 . We will find for this condition the minimum value of the parameter $\delta$.

The problem is solved in the following sequence. Let's create a new type of analysis "Design study". We will implement the connection of the parameter $\delta$, located in the graphics area, with the option "Variables" (Fig. 7) and set the limit of its extreme values from the maximum $(750 \mathrm{~mm})$ to the minimum $(350 \mathrm{~mm})$, as well as the step of changing the thickness of the jaw which is equal to $10 \mathrm{~mm}$. In the option "Limitations" we will define - the maximum stresses equal to $165 \mathrm{MPa}$. The "Target" option contains a goal to minimize the mass of the structure

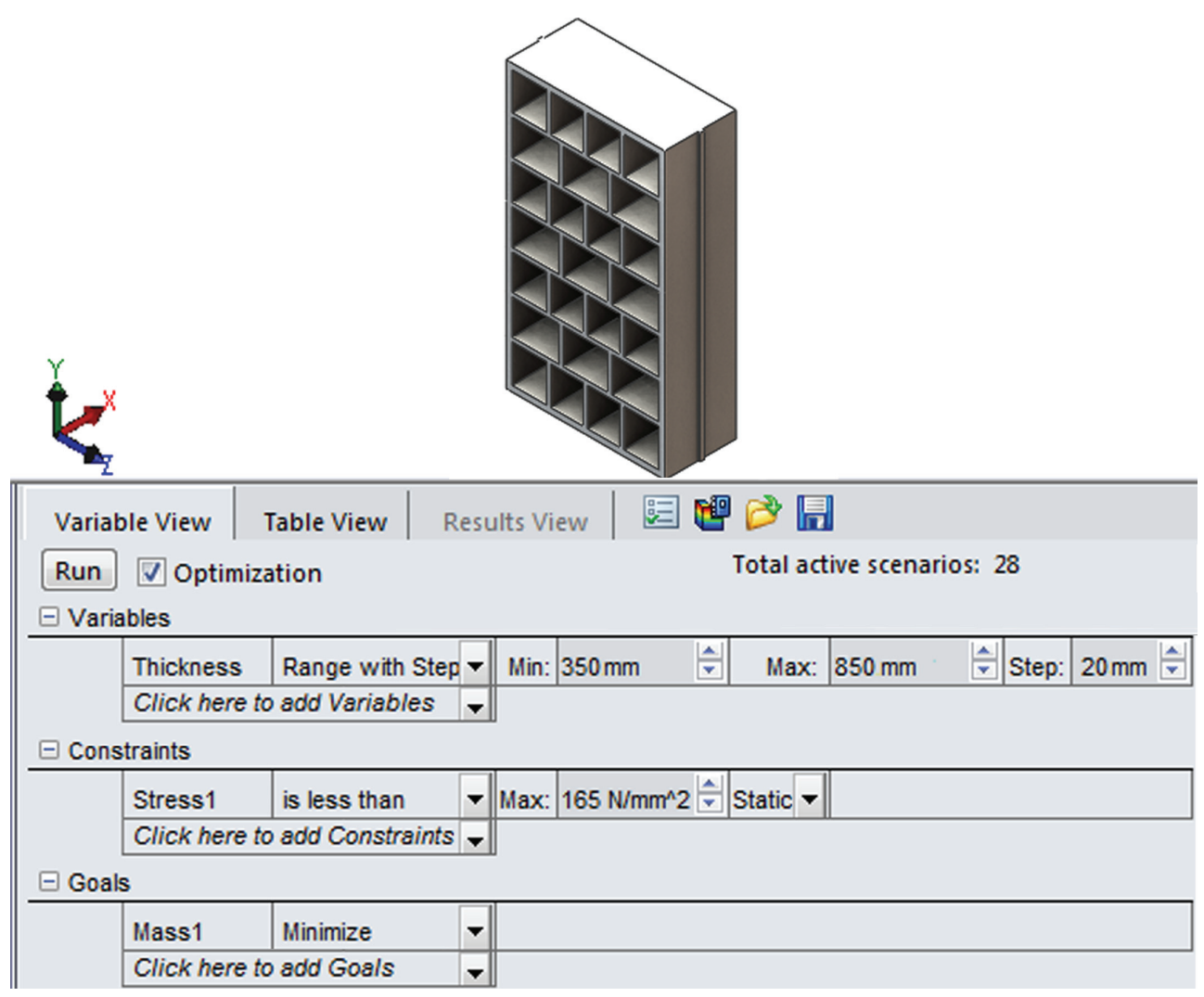

Fig. 7. Window of settings of optimization problem.

The analysis of the results of solving the optimization problem shows that the automatic search for the optimal value of the parameter $\delta$ gives the result that contradicts the physical meaning, i.e., if the case is thicker than it is provided by the test problem stipulated in the condition $(\delta=750 \mathrm{~mm})$, then the stresses exceed the allowed ones. This is due to the peculiarity of the maximum stress search algorithm, which explores all parts of the structure. In other words, the analysis of the stress values in the places of its concentration, corresponding to the zone of attachment of the jaw body to the frame, affects the value of the parameter $\delta$ (Fig. 8), which contradicts the physical meaning. Thus, the need arises in 
determining the parameter $\delta$ to analyze the picture of the stress-strain state in the body of the crusher's jaw.

\begin{tabular}{|c|c|c|c|c|c|c|c|c|c|}
\hline e View & \multicolumn{2}{|c|}{ Table View } & \multicolumn{2}{|c|}{ Results View } & \multicolumn{5}{|c|}{ 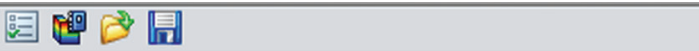 } \\
\hline \multicolumn{10}{|c|}{28 of 28 scenarios ran successfully. Design Study Quality: High } \\
\hline & & Curren & t Initial & Optimal (6) & Scenario 1 & |||Scenario & $5 \mid$ Scenario $6 \mid$ & $\mid$ Scenario 25 & Scenario 26 \\
\hline Thickness & 0 & $540 \mathrm{~mm}$ & $540 \mathrm{~mm}$ & $450 \mathrm{~mm}$ & $350 \mathrm{~mm}$ & $430 \mathrm{~mm}$ & $450 \mathrm{~mm}$ & $830 \mathrm{~mm}$ & $850 \mathrm{~mm}$ \\
\hline Stress1 & $<165 \mathrm{~N} / \mathrm{mm}^{\wedge} 2$ & 88.3251 & 88.3251 & $132.364 \mathrm{~N} / \mathrm{m}$ & $255.766 \mathrm{~N} /$ & $168.723 \mathrm{~N} /$ & $132.364 \mathrm{~N} /$ & $63.5582 \mathrm{~N} / \mathrm{m}$ & $85.7585 \mathrm{~N} / \mathrm{m}$ \\
\hline Mass1 & Minimize & 3442.62 & 3442.62 & $2494.95 \mathrm{~kg}$ & $1682.33 \mathrm{~kg}$ & $2307.1 \mathrm{~kg}$ & $2494.95 \mathrm{~kg}$ & $7144.48 \mathrm{~kg}$ & $7401.5 \mathrm{~kg}$ \\
\hline
\end{tabular}

Fig. 8. The result of solving the problem of optimization of the fixed jaw parameters.

In accordance with the Hot Spot Stress (HSS) method, to eliminate the singularity in the analysis, stresses are determined at a distance of $0.5 \cdot t$ and $1.5 \cdot t$ from the place of their concentration, where $t$ is the thickness of the rib. The nominal voltage at the sites of concentration is determined by the method of interpolation. Using the HSS technique in the SolidWorks Simulation application suite is not provided.

So, applying the HSS technique, we will solve the problem of parametric optimization of the body of the fixed jaw. To do this, we will carry out a computational experiment, which consists in the sequential calculation of the stress-strain state of the body and its analysis when the parameter $\delta$ changes in the range of $750-350 \mathrm{~mm}$ with the pitch of $20 \mathrm{~mm}$.

We will construct the dependence of the influence of the thickness of the body $\delta$ on the stress in it. We will write the results of the computational experiment into Table 1, and perform their graphical interpretation (Fig. 9).

Table 1. Values of maximum equivalent stresses in the ribs of the body of the fixed jaw.

\begin{tabular}{|c|c|c|}
\hline № & $\begin{array}{c}\text { Body } \\
\text { thickness, mm }\end{array}$ & $\begin{array}{c}\text { Maximum stress in } \\
\text { the body ribs, MPa }\end{array}$ \\
\hline 1 & 750 & 30 \\
\hline 2 & 730 & 31 \\
\hline 3 & 710 & 33 \\
\hline 4 & 690 & 35 \\
\hline 5 & 670 & 38 \\
\hline 6 & 650 & 45 \\
\hline 7 & 630 & 45 \\
\hline 8 & 610 & 49 \\
\hline 9 & 590 & 55 \\
\hline 10 & 570 & 59 \\
\hline 11 & 550 & 65 \\
\hline
\end{tabular}

\begin{tabular}{|c|c|c|}
\hline № & $\begin{array}{c}\text { Body } \\
\text { thickness, mm }\end{array}$ & $\begin{array}{c}\text { Maximum stress in } \\
\text { the body ribs, MPa }\end{array}$ \\
\hline 12 & 530 & 72 \\
\hline 13 & 510 & 79 \\
\hline 14 & 490 & 88 \\
\hline 15 & 470 & 99 \\
\hline 16 & 450 & 110 \\
\hline 17 & 430 & 124 \\
\hline 18 & 410 & 141 \\
\hline 19 & 390 & 163 \\
\hline 20 & 370 & 185 \\
\hline 21 & 350 & 220 \\
\hline
\end{tabular}

Using the method of approximation, we will find a mathematical model describing the dependence of the maximum equivalent stresses $\sigma$ on the thickness of the body $\delta$

$$
\delta(\sigma)=2632.6 \cdot \sigma^{-0.375}
$$

Graphically, this result is shown in Figure 9.

Let us determine the approximation error. The inaccuracy of the formula is estimated using the absolute root mean square $\varepsilon$ and maximum relative error $\beta$ [3], using the following expressions.

Absolute standard error of determining the dependence of the thickness of the body on the stresses which have arisen in it 


$$
\varepsilon=\frac{\sqrt{\sum_{i=1}^{n} \delta_{i}^{2}}}{n}=7.59,
$$

here $\delta_{i}$ is the difference between the vectors found by the method of approximation and obtained by the numerical experiment; $n$ is the number of nodes of the original function.

Maximum relative error of determining the thickness of the body

$$
\beta_{\max }=\frac{\varepsilon}{(\delta)_{\min }} \cdot 100 \%=2 \%
$$

A small maximum relative error serves as the basis for the following conclusion: the obtained approximation function is a satisfactory mathematical model for determining the thickness of the body of the fixed jaw taking into account the maximum equivalent stresses, therefore, the dependence can be approximated by a power function, that is, $\delta(\sigma)=2632.6 \cdot \sigma^{-0.375}$.

Similarly, we analyze the parameters of the body of the fixed jaw crusher of other sizes. The results of the analysis are shown in the form of the graphs in Figure 10, and the approximation polynomials are shown in Table 2.

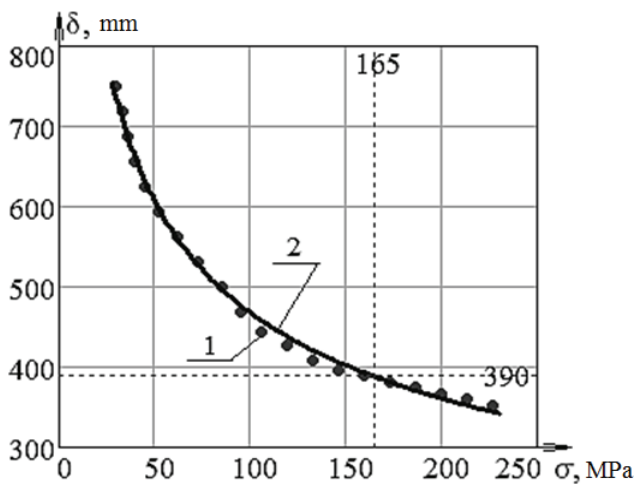

Fig. 9. Graphs of the dependence of the body thickness on the stress: 1 - the results of the computational experiment; 2 - the approximation polynomial.

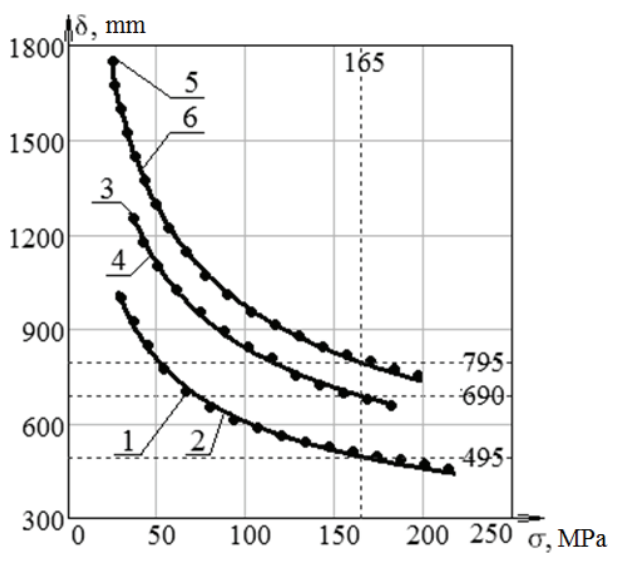

Fig. 10. Graphs of the dependence of the jaw body thickness on the stresses: $1,3,5-$ the results of a computational experiment, 2, 4, 6 the approximation polynomials for crushers sizes $1200 \times 1500, \quad 1500 \times 2100$ and $2100 \times 2500$, respectively.

Table 2. Results of optimizing the mass of the of the fixed jaw body in crushers sizes $1200 \times 1500$, $1500 \times 2100$ and $2100 \times 2500$.

\begin{tabular}{|c|c|c|c|}
\hline $\begin{array}{c}\text { Crusher size, } \\
\mathrm{mm}\end{array}$ & $\begin{array}{c}\text { Approximation } \\
\text { polynomial } \delta(\sigma)\end{array}$ & $\begin{array}{c}\text { Approximation error } \\
\varepsilon / \beta \max \end{array}$ & $\begin{array}{c}\text { Reduction of metal } \\
\text { consumption, } \%\end{array}$ \\
\hline $900 \times 1200$ & $2632.6 \cdot \sigma^{-0.375}$ & $7.6 / 2.0$ & 201 \\
\hline $1200 \times 1500$ & $3914.7 \cdot \sigma^{-0.405}$ & $11.9 / 2.2$ & 226 \\
\hline $1500 \times 2100$ & $5276.9 \cdot \sigma^{-0.399}$ & $7.6 / 1.1$ & 174 \\
\hline $2100 \times 2500$ & $6341.4 \cdot \sigma^{-0.407}$ & $11.2 / 1.3$ & 275 \\
\hline
\end{tabular}




\section{Development of guidelines for determining the optimal body thickness of the crusher's fixed jaw}

Let us determine the optimal body thickness of the fixed jaw in the crusher size $900 \times 1200 \mathrm{~mm}$. To do this, let us build a computer model of the body.

We assume that the body is made of steel $35 \mathrm{~L}$, in which the allowable stresses per shear are $47 \mathrm{MPa}$, in collapse $-120 \mathrm{MPa}$, the yield strength is $250 \mathrm{MPa}$.

Let us determine the wall thickness by the formula (1), that is, $S=750 / 12=62 \mathrm{~mm}$.

We round the obtained value to the standard, namely: $S=65 \mathrm{~mm}$.

We start modeling the jaw by creating a rectangular parallelepiped, for which we create a sketch on the "Right" plane. From the starting point of the coordinates, draw a rectangle of the following dimensions: width $L=1200 \mathrm{~mm}$, height $H=2160 \mathrm{~mm}$. Using the "Extruded Boss" tool, we give the parallelepiped a thickness of $750 \mathrm{~mm}$. We set "View from the right" for the spatial figure.

We choose the "Shell" element for the further design of the shape. In the "Parameters" group window from the "Delete faces" list, we take the front face of parallelepiped, and assign the value " $S$ " to the "Thickness" parameter. Through the "Equation" tool, set a rounded value to this size.

Rib reinforcements are used to increase the rigidity and strength of cast parts and as a means of improving the casting [3]. The method of locating the ribs should help to improve the filling of the casting elements with material, prevent the occurrence of shrink holes and internal stresses there.

At the tops of the ribs, it is necessary to model the fillets with a radius of at least $1 \mathrm{~mm}$. The tops of the ribs with a thickness of less than 6 to $8 \mathrm{~mm}$ should be rounded off (rounding radius $R=0.5 \cdot S$ ). The base of the ribs should be connected to the wall by fillets with a radius of $R \approx 0.5 \cdot S$.

More rapid cooling of the castings is achieved by reducing the thickness of the ribs. So, for the outer ribs, it is usually $(0.6-0.7) S$, and for the internal ones, given the deteriorated heat sink, $-(0.5-0.6) S$, where $S$ is the wall thickness.

In case of double-sided coating of the part with ribs to have the ribs staggered in order to avoid local accumulations of metal, as well as to reduce shrinkage stresses

It is necessary to provide for the elimination of metal accumulations when the ribs are mated with the walls at an angle by spreading the first ones. Arrays of material at the junction of several ribs are removed using an annular joint.

Thus, it is expedient to reinforce the body by applying wafer ribs (Fig. 11). Such ribs are well molded on flat surfaces or on surfaces that have a small curvature, and they must be parallel to the plane of the connector of the form [7].

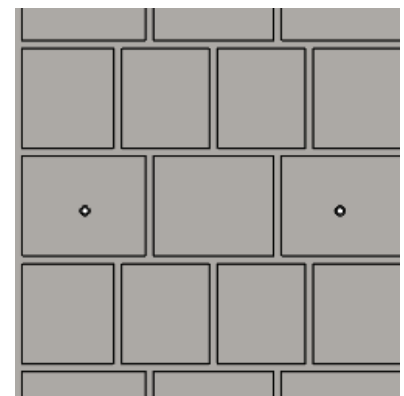

Fig. 11. Scheme of rib reinforcement of the body of the crusher's fixed jaw.

On the front face we create a sketch of the reinforcement of the fixed jaw with such geometrical dimensions of the ribs, calculated by the formulas (3) - (5): 


$$
T_{1}=2160-2 \cdot 65 / 7=290.7 \mathrm{~mm} \text {. }
$$

We round the received value: $T_{1}=290 \mathrm{~mm}$.

$$
T_{2}=1200-2 \cdot 65 / 4=268.7 \mathrm{~mm} .
$$

We consider that $T_{2}=270 \mathrm{~mm}$.

$$
T_{3}=1200-2 \cdot 65 / 3=358.3 \mathrm{~mm} \text {. }
$$

We round the received value: $T_{3}=360 \mathrm{~mm}$.

We will assume that the thickness of the ribs according to dependence (2) is equal to $45 \mathrm{~mm}$.

The fixed jaw, having the ledge, is connected to the bed with the help of a recess (groove) in it. This ledge works in cut and bearing. The width and height of the ledge is determined by the following formulas:

$$
\begin{gathered}
l_{c}=\frac{Q}{2 H \cdot \tau}=\frac{7 \cdot 10^{6}}{2 \cdot 2160 \cdot 47}=34.5 \mathrm{~mm} \\
\delta_{c}=\frac{Q}{2 H \cdot \sigma}=\frac{7 \cdot 10^{6}}{2 \cdot 2160 \cdot 120}=13.5 \mathrm{~mm},
\end{gathered}
$$

here the crushing force is $Q=2.7 \mathrm{MPa} ; H$ - the height of the fixed jaw, mm; $\tau-$ permissible stress on the cut, MPa; $\sigma$ is the permissible stress for bearing, MPa.

Let us perform rounding of values, that is, $l_{c}=35 \mathrm{~mm} ; \delta_{c}=15 \mathrm{~mm}$.

Next, we simulate the element of the body connection with the bed. To do this, on the upper face of the fixed jaw we create a sketch using the calculated parameters. Using the "Extruded Boss" tool, extend it to the "Before the surface" distance, pointing to the lower face of the jaw (Fig. 12).

Using the mathematical model (6), we determine the thickness of the jaw body, that is,

$$
\delta(165)=2632.6 \cdot 165^{-0.375}=387.997 \mathrm{~mm} .
$$

As a result of the actions performed, we have received a solid-state parametric computer model of the jaw body, shown in Figure 13.

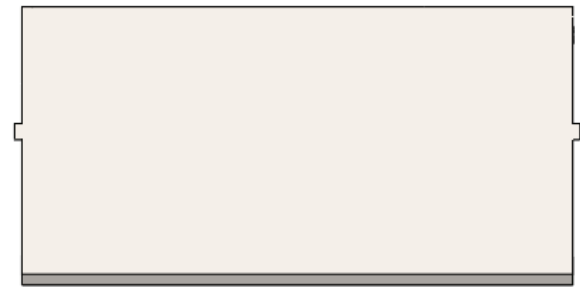

Fig. 12. Elements of the jaw with sidewalls.

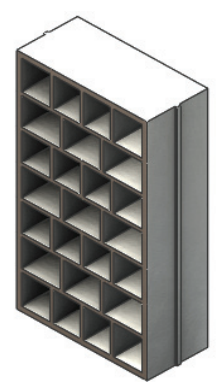

Fig. 13. Parametric computer model of the body of the fixed jaw of the crusher size $900 \times 1200$. 
Let us round the resulting value of the thickness of the body to $390 \mathrm{~mm}$ and substitute it into the calculation using the application program SolidWorks Simulation. The result of this calculation will be a plot of the stresses arising in the housing (Fig. 13), from which it can be seen that they are below the allowable, and the safety margin of 250/137.8 $=1.8$.

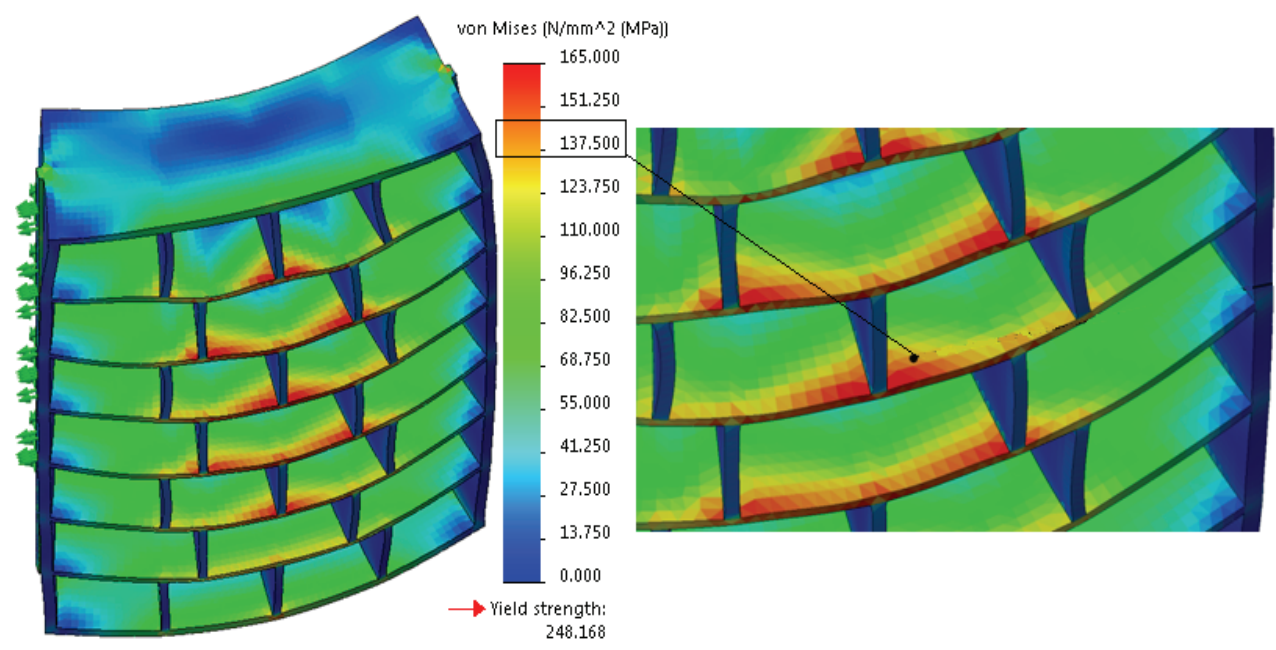

Fig. 13. The diagram of stresses in the body of the fixed jaw $(\delta=390 \mathrm{~mm})$.

\section{Conclusions}

Parametric optimization of the design of the crusher jaw body according to the criterion of the minimum of its mass under given strength conditions is a topical scientific task.

Standard algorithms for finding the optimal thickness of the body under the given criteria of strength lead to its significant overestimation, since the maximum equivalent stresses are chosen not in the ribs of the structure, but in the stress concentrators, which represent its attachment points.

For the first time, the algorithm for parametric optimization of a structure has been proposed, consisting of a sequence of computational experiments with subsequent analysis of the obtained calculation results based on the HSS (Hot Spot Stress) method.

The use of the proposed algorithm makes it possible to substantiate scientifically the reduction of the mass of the body of the crusher's fixed jaw by $200 \%$.

Processing the results of computational experiments in the study of bodies of commercially available jaw crusher makes it possible to construct approximation polynomials used to calculate the thickness of the body of the fixed jaw for given values of allowable stresses.

\section{References}

1. Zabolotnyi, K.S., Panchenko, O.V., Zhupiiev, O.L., Polushyna, M.V. (2018). Influence of parameters of a rubber-rope cable on the torsional stiffness of the body of the winding, Scientific bulletin of the National Mining University, 5, 54-63

2. Zabolotnyi, K., Zhupiiev, O., Molodchenko, A. (2018). The effect of stiffness of shoe brakeelements on the distribution of contact pressures, Scientific bulletin of the National Mining University, 2 (164), 39-46

3. Zabolotny, K., Panchenko, E. (2010). Definition of rating loading in spires of multilayer 
winding of rubberrope cable, New Techniques and Technologies in Mining, 223-229

4. Moskalyova, T.V., Polushyna, M.V. (2015). Cross way of fastening steel ropes to a singledrum mine hoisting plant with the location of pulleys on the same axis, Scientific bulletin of the National Mining University, 3, 56-62 